\title{
Coordination of the closed loop supply chain with retailers' competition Wang Ting
}

\author{
Department of Mathematics, QiLu Normal University, Jinan 250013, China \\ redandhair1981@sina.com
}

Keywords: the closed loop supply chain; remanufacture; return mechanism; competition.

\begin{abstract}
To reflect the coordination in the supply chain of perishable products with free competition, a single manufacturer and two retailers supply chain model facing the stochastic demand in relation with different prices and the return mechanism is established. The analysis shows that the profit of total supply chain without competition is obviously fewer than that with competition, and through the special linear model the paper employs the result, also gives the optimal price and order quantity in the coordination of the supply chain.
\end{abstract}

\section{Introduction}

According to the definition by logistics' administrative association, closed loop supply chain means obverse and reverse supply chain from consumption to production which is to obtain the value again or dispose of the waste correctly. Also contains planning, practicing and controlling raw materials, products and related information effectively and with low cost.

We can find two differences between reverse and obverse supply chain: one is the different aims; two is the opposite flowing direction between logistics and information.

Since the aim of obverse supply chain is to achieve the value of products and service, the reverse supply chain is to explore the potential value of the defected products and the waste, this paper defines that: the closed loop supply chain is a complete ring-like supply chain system which contains reverse process on the traditional obverse logistics. Through the product's obverse payment and reverse recycling, the split-ring process called "the resources-production-expense-the abandoned" turned to the closed loop feedback cyclic process of "the resources-production expense-regeneration resources”. This definition contains double directions' move of logistics and information in the supply chain. The closed loop supply chain is divided into four types of operational model, namely based on recycling, on reuse, on repair/refurnishing/cannibalization and on remanufacturing. The effective management to the closed loop supply chain not only may promote the ecological environment optimization, social economy sustainable development, simultaneously also may bring the obvious economic efficiency for the enterprise, strengthen his/her competitive advantage.

Cheng-Han $\mathrm{Wu}(2012)$ discuss the product's design and pricing strategy based on remanufacture. Jing and Bell(2009) research the order in the closed loop supply chain with the determined and stochastic demand. Julien and Teunter discuss the resale of the returns reflect the supplt chain in the single period. Savaskan, Bhattacharya and Wassenhovel(2004) constructed a reverse logistics model with the retailers' recycling, and advised a coordinated plan based Nash equilibrium, but it is a certain gap with reality because there is only one supplier and one retailer in the model.

In this article we focus on the problem with two competed retailers in the selling and recycling, considering competition about retail price and non-retail price. Also we analysis the transfer price, recycling price and retail price of the system in the market based on retailers pricing and system pricing in order to show the impact of which the total property in the supply chain with competitions.

\section{The problem and the model.}

We consider a remanufacturing supply chain model with one manufacture and two retailers who are responsible for selling the products and their recycling. In the obverse logistics, there is quantity competition in retailers, also in the reverse course, recycling is determined by recycling price and the customs' favor. 
Based on Nash equilibrium, retail price rises with the wholesale price of the manufacture. In the recycling, we discuss the scale and relationship between transfer price and recycling price.

Suppose the demand of a retailer is the linear function of its retail price, non-price competed factors and the opponent's retail price, so the demand is determined. While recycling quantity is the function of recycling price which is determined by the recycling price of himself and the other, also determined by fixed recycling expenses.

In the market, retail price of retailer $R_{1}$ and $R_{2}$ are $P_{01}$ and $P_{02}$, the demand is $D_{1}$ and $D_{2}$, recycling price is $P_{1}$ and $P_{2}$, recycling quantity is $I\left(P_{1}\right), I\left(P_{2}\right)$,

$D_{i}=F_{i}+a-b P_{0 i}+c P_{0 j} \quad(i \neq j) . F_{i}$ is demand quantity attracted by non-price factor, $a$ is the maximum demand by self factor, $b$ is the negative factor according to the demand of self price, $c$ is positive according to competed opponent's price.

$a, b, c>0, F_{i}>0, b>c$. According to the express, we know that price of ourselves rising or that of opponent declining lead to local demand decline, which tally with market rule. $I\left(P_{i}\right)=m P_{i}^{k}-n P_{j}^{k}-G_{i}(i \neq j)$ 。 $m$ is the positive factor by self recycling price according to local recycle, $n$ is negative to opponent recycle. $G_{i}$ is fixed expenses. $m, n>0, G_{i}>0, m>n$.

From the hypothesis, the members' profit function in the system as follows:

$$
\begin{aligned}
& \Pi(M)=\left(\omega-C_{m}\right)\left(D_{1}+D_{2}\right)+\left(C_{m}-C_{r}-A\right)\left[I\left(P_{1}\right)+I\left(P_{2}\right)\right] \\
& \Pi\left(R_{1}\right)=\left(P_{01}-\omega\right)\left(F_{1}+a-b P_{01}+c P_{02}\right)+\left(A-P_{1}\right)\left(m P_{1}^{k}-n P_{2}^{k}-G_{1}\right) \\
& \Pi\left(R_{2}\right)=\left(P_{02}-\omega\right)\left(F_{2}+a-b P_{02}+c P_{01}\right)+\left(A-P_{2}\right)\left(m P_{2}^{k}-n P_{1}^{k}-G_{2}\right) \\
& \Pi=\Pi(M)+\Pi\left(R_{1}\right)+\Pi\left(R_{2}\right) \\
& \quad=\left(P_{01}-C_{m}\right) D_{1}+\left(P_{02}-C_{m}\right) D_{2}+\left(C_{m}-C_{r}-P_{1}\right) I\left(P_{1}\right)+\left(C_{m}-C_{r}-P_{2}\right) I\left(P_{2}\right)
\end{aligned}
$$

\section{The pricing problem with different retailers}

While $\omega$ is determined by manufacture, retailers compete though the retail price.

$$
\begin{aligned}
& \frac{\partial \Pi\left(R_{1}\right)}{\partial P_{01}}=F_{1}+a+c P_{02}+b \omega-2 b P_{01}, \frac{\partial \Pi\left(R_{2}\right)}{\partial P_{02}}=F_{2}+a+c P_{01}+b \omega-2 b P_{02} \\
& \frac{\partial^{2} \Pi\left(R_{1}\right)}{\partial P_{01}^{2}}=-2 b<0, \quad \frac{\partial^{2} \Pi\left(R_{2}\right)}{\partial P_{02}^{2}}=-2 b<0,
\end{aligned}
$$

$\Pi\left(R_{i}\right)$ is the convex function of $P_{0 i}(i=1,2)$, so $\Pi\left(R_{i}\right)$ has the optimal solution. According to the demand function and countermeasure, there is Nash equilibrium between $P_{01}$ and $P_{02}$.

$$
\begin{aligned}
& P_{01}=\frac{2 b F_{1}+c F_{2}+2 b^{2} \omega+b c \omega+2 a b+a c}{4 b^{2}-c^{2}} \\
& P_{02}=\frac{2 b F_{2}+c F_{1}+2 b^{2} \omega+b c \omega+2 a b+a c}{4 b^{2}-c^{2}} \\
& P_{01}+P_{02}=\frac{F_{1}+F_{2}+2 b \omega+2 a}{2 b-c}
\end{aligned}
$$

It is obvious that retail price is the increase function of $\omega$ which is determined. 
Furthermore, we consider the optimal wholesale price: $\frac{\partial\left(P_{01}+P_{02}\right)}{\partial \omega}=\frac{2 b}{2 b-c}$, $\frac{\partial \Pi(M)}{\partial \omega}=F_{1}+F_{2}+2 a-(b-c)\left(P_{01}+P_{02}\right), \quad \frac{\partial^{2} \Pi(M)}{\partial \omega^{2}}=-\frac{(b-c) 2 b}{2 b-c}<0$, so $\Pi(M)$ is the convex function of $\omega$. Then, $\frac{\partial \Pi(M)}{\partial \omega}=0, \omega=\frac{F_{1}+F_{2}+2 a}{2(b-c)}$

$$
\begin{aligned}
& P_{01}^{*}=\frac{3 b}{2 b+c} F_{1}+\frac{2 b^{2}+3 a b c-2 c^{2}}{4 b^{2}-c^{2}} F_{2}+2 a \\
& P_{02}^{*}=\frac{3 b}{2 b+c} F_{2}+\frac{2 b^{2}+3 a b c-2 c^{2}}{4 b^{2}-c^{2}} F_{1}+2 a
\end{aligned}
$$

If $F_{1}>F_{2}$, than $P_{01}>P_{02}$, the retail price is high by the retailer who is good at non-price competition, followed the higher profit. So, retailers inclined to improve the service to empower their competition.

Now we discuss the recycling price. The manufacture followed by retailers, as the manufacture first announce the wholesale price and recycling price, retailers reflect at once to determine the price in order to max the profit. Solution as follows by reverse induction:

$$
\begin{aligned}
& \frac{\partial \Pi\left(R_{1}\right)}{\partial P_{1}}=n P_{2}^{k}+G_{1}+A k m P_{1}^{k-1}-k(m+1) P_{1}^{k} \\
& \frac{\partial \Pi\left(R_{2}\right)}{\partial P_{2}}=n P_{1}^{k}+G_{2}+A k m P_{2}^{k-1}-k(m+1) P_{2}^{k}
\end{aligned}
$$

suppose $A$ is determined, meanwhile recycling quantity is the linear function of the recycling price, $k=1$,

$$
\begin{array}{ll}
\frac{\partial \Pi\left(R_{1}\right)}{\partial P_{1}}=n P_{2}+G_{1}+A m-(m+1) P_{1}, & \frac{\partial^{2} \Pi\left(R_{1}\right)}{\partial P_{1}^{2}}=-(m+1)<0 \\
\frac{\partial \Pi\left(R_{2}\right)}{\partial P_{2}}=n P_{1}+G_{2}+A m-(m+1) P_{2}, & \frac{\partial^{2} \Pi\left(R_{2}\right)}{\partial P_{2}^{2}}=-(m+1)<0
\end{array}
$$

While $\Pi\left(R_{i}\right)$ is the convex function of $P_{i}$, so according to $\frac{\partial \Pi\left(R_{1}\right)}{\partial P_{1}}=0$,

$$
\begin{aligned}
& \frac{\partial \Pi\left(R_{2}\right)}{\partial P_{2}}=0, \text { we get } P_{1}=\frac{(m+1) G_{1}+n G_{2}+A m(m+n+1)}{(m+1)^{2}-n^{2}}, \\
& P_{2}=\frac{(m+1) G_{2}+n G_{1}+A m(m+n+1)}{(m+1)^{2}-n^{2}}, P_{1}+P_{2}=\frac{G_{1}+G_{2}+2 A m}{m+1-n}
\end{aligned}
$$

It is obvious that recycling price is the increase function of transfer price $A$ which is determined.

\section{The pricing problem with the system}

When the system is at the best state, the members' profit is not certainly optimal, but it's true that the total profit can improve. In the system, the order quantity is $F_{1}+F_{2}+2 a-(b-c)\left(P_{01}+P_{02}\right)$, recycling quantity is $(m-n)\left(P_{1}+P_{2}\right)-G_{1}-G_{2}$, the total profit is $\Pi$, from(1), $\Pi$ is not related with $\omega$ and $A$, so the decision is retail price and recycling price, while the wholesale price and transfer price only affect the optimal profit's sharing not the total profit of the system.

$$
\frac{\partial \Pi}{\partial P_{01}}=F_{1}+a+b C_{m}+c P_{02}-2 b P_{01}, \quad \frac{\partial \Pi}{\partial P_{02}}=F_{2}+a+b C_{m}+c P_{01}-2 b P_{02}
$$


The $\Pi$ is the strict convex function, so we get

$$
P_{01}^{*}=\frac{2 b F_{1}+c F_{2}+\left(2 b^{2}+b c\right) C_{m}+2 a b+a c}{4 b^{2}-c^{2}} P_{02}^{*}=\frac{2 b F_{2}+c F_{1}+\left(2 b^{2}+b c\right) C_{m}+2 a b+a c}{4 b^{2}-c^{2}}
$$

Similarly: $\frac{\partial \Pi}{\partial P_{1}}=-2 m P_{1}+n P_{2}+G_{1}+m\left(C_{m}-C_{r}\right), \frac{\partial \Pi}{\partial P_{2}}=-2 m P_{2}+n P_{1}+G_{2}+m\left(C_{m}-C_{r}\right)$

$$
P_{1}^{*}=\frac{2 m G_{1}+n G_{2}+\left(2 m^{2}+m n\right)\left(C_{m}-C_{r}\right)}{4 m^{2}-n^{2}}, P_{2}^{*}=\frac{2 m G_{2}+n G_{1}+\left(2 m^{2}+m n\right)\left(C_{m}-C_{r}\right)}{4 m^{2}-n^{2}}
$$

It's the same that the retail price is high by the retailer who is good at non-price competition, followed the higher profit, also with the change of the recycling price. So, retailers inclined to improve the service to empower their competition with the precondition of ensuring the total profit. In reality, the optimal price ensure the coordination of the supply chain.

\section{References}

[1] Cheng-Han Wu. Product-design and pricing strategies with remanufacturing [J]. European Journal of Operational Research, 222(2012) $204-215$.

[2]Jing Chen, Peter C. Bell. The impact of customer returns on pricing and order decisions[J]. European Journal of Operational Research, 195(2009)280 - 295.

[3]Julien Mostard, Ruud Teunter. The newsboy problem with resalable returns: A single period model and case study[J]. European Journal of Operational Research, 169(2006)81 - 96.

[4] Dimitrios Vlachos, Rommert Dekker. Return handling options and order quantities for single period products[J]. European Journal of Operational Research, 151(2003)38 - 52.

[5] SAVASKAN R C,BHATTACHARYA S, WASSENHOVEL. Closed-loop supply chain models with product remanufacturing[J].Management Science, 50(2) (2004)239 - 252.

[6] Mostard, J., Teunter, R. The newsboy problem with resalable returns: A single period model and case study. European Journal of Operational Research , 169(2006)81 - 96.

[7] GuideJr V D R, Jayaraman V, Linton J D. Building contingency planning for closed loop supply chains with product recovery [J]. Journal of Operations Management, 21(3) (2003)2592-279. 